\title{
Clinical Medicine and Science
}

$\mathrm{I}^{\mathrm{N}}$ $T$ the anniversary address delivered before the Royal Society on November 30, the president, Sir Frederick Gowland Hopkins, devoted particular attention to the relation between clinical medicine and science.

After alluding to the extraordinary progress which atomic physics continues to make and the remarkable response of atoms to various forms of treatment, he pointed out that the subject he had chosen is of special interest to the Royal Society inasmuch as it has received large bequests to support original research in medicine devoted to improvement in the treatment of disease and the relief of human suffering. He illustrated the close relationship between practice in the wards and activity in the laboratory by two recent advances which, taken together, served in a sense as a text for the rest of his address.

The first of these was the investigation carried out by means of the oscillograph method by the Foulerton research professor, Prof. E. D. Adrian, with his colleague, Mr. Brian Mathews, on the electrical changes which take place in the brain, with the object of relating the potential changes in the brain with the changes in individual nerve cells. The rhythmic activities of the human brain recorded as a series of waves after passing through the skull were shown by this method to be temporarily abolished by concentrated thought such as that involved in mental arithmetic. Sir Frederick suggested that further development of the technique might serve the clinical investigator of the brain as the cardiograph has served those concerned with the heart.

The second example of the assistance given to clinical medicine by the laboratory is furnished by the study of the virus of influenza, in which Mr. Laidlaw, in collaboration with Drs. Andrewes and Wilson Smith, who had previously shown that influenza can be transmitted to the ferret, proved that the mouse can also be infected, and thereby made the approach to various aspects of the problem much easier. Such progressive research, due entirely to the laboratory, is of prime importance alike to clinical and laboratory medicine, and being inspired by clinical experience illustrates the now generally recognised interdependence of the ward and the laboratory.

Sir Frederick next dealt with the uneasiness apparently felt by some physicians with regard to the introduction of multitudinous laboratory methods into the domain of diagnosis. While it is an open question as to whether reliance on laboratory reports destroys the clinical sense, as some are inclined to believe, he instanced the objections raised to the use of the stethoscope when it was first introduced by Laennec, on the ground that it was fatal to the dignity of the physician and brought only discomfort to the patient. Although a few may still be inclined to regard each diagnostic aid from the laboratory with a similar distrust, it is to be hoped that the practitioner will be ready to avail himself of every diagnostic assistance without impairment of his clinical sense.

Sir Frederick then proceeded to give a historical sketch of clinical science based on the classification of Sir Thomas Lewis, who grouped its activities in three categories. The first was the discovery of disease, or a clear description of specific diseases or states, which has been the aim of enlightened clinicians ever since the escape of medicine from Galenic authority in the seventeenth century. The second was experimental work on clinical cases, and the third the application of physiological discoveries to human material. The ignorance of the medical profession as to the nature of disease when experimental study of it began and the Royal Society was founded was illustrated by the appalling treatment of its founder, Charles II, in his last illness, when Galenic teaching was still predominant. How William Harvey, the indisputable father of clinical science, who had a thorough contempt for the Galenic teaching of his contemporaries, would have regarded such treatment, is best left to the imagination.

It is noteworthy that of the $\mathbf{1 4 6}$ original fellows of the Royal Society in 1663,24 , or nearly one sixth of the whole, were medical practitioners, while only one outstanding physician, Thomas Sydenham, did not join it, doubtless owing to his hatred of theory and any kind of deductive speculation. Sydenham, who was a pioneer in the discovery of disease in Sir Thomas Lewis's sense, held that each disease was an entity apart from the particular patient, and taught that the clinician's task was to reduce diseases to certain definite species, as botanists were doing in the classification of plants.

Continuing his historical sketch, Sir Frederick pointed out that there was no outstanding advance in the theory or practice of medicine in the eighteenth century, and that it was not until the rise of the great French school in the early years of the nineteenth century that real medical progress took place. With the notable exception of Broussais, who vehemently opposed the doctrine of specificity, the principal physicians in Paris shared Sydenham's belief in specific diseases as entities, and classified them accordingly, but they added something to mere observation of symptoms 
as a basis for their classification. Thus Bichat, who was a profound student of morbid anatomy, emphasised the importance of relating the specificity of each disease to the nature of the fundamental tissues attacked rather than to the disturbances in individual organs.

The views of Broussais, who rejected the conception of diseases as entities and insisted that disorders of function should receive more attention, were supported by the contemporary school of Vienna, which maintained that the task of the physician was to identify in the patient the various individual lesions of morbid anatomy.

Meanwhile, the leading English-speaking physicians, such as Addison, Bright and Hodgkin in London, and Graves, Stokes, Cheyne and Adams in Dublin, were bringing about real advances in clinical medicine by the clear demonstration of diseases and clinical states with which their names are associated.

The great movement in German medical thought which culminated in the middle of the nineteenth century was associated with a strong reaction against all claims of specificity based on the mere assembling of associated symptoms. Virchow in particular maintained that French and British ontology had impeded real progress in scientific medicine, and believed that with its destruction the use of a treatment falsely called specific would also disappear.

On the other hand, the doctrines of Sydenham and the leading representatives of the French school, among whom Sir Frederick omits to mention Bretonneau, to whom Trousseau was indebted for his views on specificity, were later confirmed by the discoveries of Pasteur, whose laboratory work did more to clarify medical thought than most of the doctrines emanating from the medical schools, inasmuch as he replaced a mysterious something by the highly objective micro-organism as the cause of certain infectious diseases. Sir Frederick, however, pointed out that the presence of bacillus or virus, though an efficient cause, is not necessarily a sufficient cause of a disease, and that the constitutional factor, on which much emphasis has been laid in recent years, must also be considered in the causation, especially in the case of non-infectious diseases, and is doubtless susceptible of analysis by modern methods.

In forecasting the activities of clinical science, Sir Frederick expressed his conviction that the scope for really controlled experiments applicable to the intact human body is limited. He suggested that there are relatively few experimental fields for clinical science besides those of cardiology and related subjects in which Sir Thomas Lewis is engaged, and the studies of Prof. Edward Mellanby on ,nutrition in relation to disease (see NATuRE of December 1, p. 830). On the other hand, there are many wide fields in laboratory science, and particularly those of biophysics and biochemistry, the cultivation of which will continue to benefit medicine.

Sir Frederick deprecated the growing tendency in Great Britain and elsewhere to distribute the funds provided for medical research in the endowment of the clinic at the expense of fundamental biological science, as he is convinced that such a policy will sterilise advance. In support of this conviction, he quoted Charcot's dictum that the clinic "without scientific renovation soon becomes a belated routine and, as it were, stereotyped".

In conclusion, Sir Frederick expressed the hope that the Royal Society, though its special duty is the encouragement of pure science, will continue to endow whatever fields of research might at any moment promise to offer most help towards progress, whether in the narrow region of clinical science or in the wider regions of pure science.

\section{Maison de la Chimie, Paris}

$\mathrm{T}$ $\mathrm{HE}$ inauguration of the Maison de la Chimie by the President of the French Republic, which had been postponed for a month owing to the assassination of the King of Yugoslavia at Marseilles, took place on December 1. An international gathering of unusual brilliance witnessed this important step towards the co-ordination of scientific endeavour. Twenty-four countries were represented, and among the delegates from Great Britain were Prof. H. E. Armstrong (Royal Society and Federal Council of Chemistry), Mr. W. A. S. Calder (Institution of Chemical Engineers), Prof. C. S. Gibson (Royal Society), Dr. T. A. Henry (Wellcome Research Institution), Mr. Emile Mond
(Federal Council of Chemistry and Chemical Society), Sir Robert Robertson (British Government), Mr. Richard Smith, Mr. Edwin Thompson and Prof. J. F. Thorpe (Institute of Chemistry), Mr. Thomas Pearson, of the International Chamber of Commerce and Sir Robert Cahill of the British Embassy. An excellent copy of the painting by Sir Thomas Lawrence of Sir Humphrey Davy was given to the "Maison de la Chimie" by a group of English chemists, whilst Mr. and Mrs. Emile Mond presented a replica of the bust of Faraday, the original of which is at the Royal Institution.

In the large and imposing hall, which will serve as meeting hall for future congresses, speeches 